\title{
PROCESSO DE ENFERMAGEM: REFLEXOES ACERCA DA TERMINOLOGIA UTILIZADA
}

\author{
Emilia Luigia Saporiti Angerami* \\ Emilia Campos de Carvalho**
}

ANGERAMI, E.L.S.: CARVALHP, E.C. de. Processo de enfermagem: reflexões acerca da terminologia utilizada. Rev. Esc. Enf. USP, São Paulo, 21(n̊/especial)29-33, 1987.

\section{INTRODUÇĀO}

O Processo de Enfermagem como metodologia de assistência, foi introduzido no Brasil na década de 60 e segundo Angerami e Boemer (1964) o modelo descrito por HORTA (1979) "foi incorporado pelos enfermeiros brasileiros em qualquer de seus campos de atuação, chegando mesmo a confundir-se com a teoria das necessidades humanas básicas proposta pela mesma autora".

Este fato pode ser observado pelos autores do presente estudo quando ministraram cursos de Processo de Enfermagem, em nível de Pós-Graduação: a expectativa dos alunos, visava aprofundamento do conhecimento e da aplicação na prática do Processo de Enfermagem proposto por Horts.

Esta questão de centrar o assunto "Processo de Enfermagem" apenas em um autor e na metodologia gerou a preocupação de limitar a visão do aluno. Portanto, já havíamos introduzido, em anos anteriores, o estudo das fases do processo de Enfermagem descrito por outros autores, bem como o estudo das fases do método de solução de problemas, também focalizando as abordagens de diferentes autores.

Durante o estudo crítico das fases destas metodologias de assistência surgiram questionamentos que nos inquietaram pela sua relevância na Enfermagem:

1) A existência de semelhanças e diferenças nas fases do processo de enfermagem e no método de solução de problema;

2) O emprego de terminologia relativa ao processo de enfermagem e ao método de solução de problema.

$\mathrm{Na}$ busca de aprofundar o conhecimento e análise das questões que permeiam a Enfermagem planejamos o curso de Processo de Enfermagem: análise $e$ etapas operacionais para ser ministrado em três unidades: na primeira foi considerada a história na qual foram estudadas as trans.

\footnotetext{
* Professor Titular da Escola de Enfermagem de Ribeirão Preto - USP.

* Professor Assistente Doutor da Escola de Enfermagem de Ribeirão Preto - USP.
} 
formações do planejamento da assistência; na segunda unidade estudou-se a terminologia em Enfermagem tendo como referencial teórico a semiótica; na terceira unidade abordou-se a Metodologia do Processo de Enfermagem em confronto com o método de Solução de Problema.

Em que se pese a relevância e importância de pesquisas relacionadas às questões da metodologia da assistência e a sua incorporação à prática, o presente estudo estará direcionado à questão da terminologia em Enfermagem.

\section{REFERENCIAL TEORICO}

A terminologia está inserida num problemá maior que é o da significação. Este é de considerável relevância para todos os ramos do conhecimento.

Alguns autores defendem a contrução de uma meta-linguagem científica indissociável da construção da própria ciência e a primeira con. dição para seu crescimento (Pais, 1976).

Outros preconizam a existência de terminologia como indispensá. vel ao desenvolvimento de uma profissão, por se constituir parte integrante do seu contexto teórico-prático (Simões, 1980). Neste caso, espera-se que os termos empregados entre elementos de um grupo profissional transmitam a todos a mesma significação.

Embora na Enfermagem esta questão se apresente incipiente não o é enquanto ciência e para outros campos do conhecimento.

No Brasil esta problemática foi abordada por Carvalho (1969), ao se referir à utilização pela Enfermagem de terminologia das Ciências da Saúde e seus próprios termos, todavia, necessitando de definição e uniformização. Esta autora sugeriu a construção de um glossário, proposta esta que, de certa forma, é alcançada por Simões (1980).

Outro exemplo de estudo neste campo, é o abordado por Bloch (1974) sobre os termos cruciais em Enfermagem e seus significados.

A problemática relativa ao termo "The Nursing process" também é estudada por Henderson (1982) que o examina semanticamente ao questionar a sua adequacidade, sua evolução histórica e relação com solução de problemas no trabalho da enfermeira.

A questão da significação pode ser vista sob vários prismas. Na semiótica são estudados os princípios gerais que regem o funcionamento dos sistemas de sígnos ou códigos. São examinados vários tipos de signos e a constituição de sistemas de signos, ou seja, a linguagem.

A principal função dos signos está em permitir "partilhar" algo com alguém, prestar informes a alguém, de modo que o signo se associe aos objetos e as pessoas que participa, de maneira bem determinada, social. mente condicionado, do processo da comunicação. 
A semiótica considera o signo como uma unidade semiótica que subs. titui o objeto a conhecer, representando-o aos individuos e apresentando-se-lhes em lugar do objeto.

Combina um elemento perceptível ou sensivel (significante) a um elemento intelegivel (significado) para construir a relação entre eles (significação). Isto pode ser aplicado no seguinte exemplo de Enfermeiro onde, se o órgão é lingüístico, o complexo sonoro audível que encerra o significado é o significante (Ex: Enfermeiro); a imagem mental invocada pela seqüência fônica é o significado; o resultado (relação recíproca entre nome e conceito) é a significação: Enfermeiro.

A significação está relacionada ao uso de palavra, ou seja ao contexto cultural em que é utilizada.

Portanto cada signo tem seu valor no sistema de que faz parte, é sempre institucional por existir apenas para um número limitado de usuário, sem autonomia fora do grupo social.

Sob o ponto de vista semântico, o que se observa em Enfermagem é o emprego de homônimos em substituição a sinônimos.

O propósito de estudos neste campo é o de afastar homônimos para se obter uma definição inequívoca de significado. Portanto a problemática relaciona-se em determinar o significado do signo e que convêm ao signo.

Cumpre-nos destacar que a terminologia não elimina totalmente os equívocos e confusões em torno do significado. E necessário explicitar o contexto em que é utilizado.

Alguns trabalhos mostram as diferentes significações dadas a um termo no âmbito de Enfermagem, como por exemplo, o estudo desenvolvido por Lane e Ral (1983) sobre os conceitos da palavra "complaine" entre enfermeiros e estudantes de enfermagem; salientam a existência de um "código de termos em enfermagem" e que o mesmo influencia a impressão que a enfermeira tem sobre os pacientes. Evidenciam uma divergência entre o significado denotativo (do dicionário) e o conotativo especialmente na área de enfermagem.

Desta natureza são as pesquisas de Horta e Kannebley, Horta (1976) sobre o significado da "dor" para pacientes, estudantes e profissionais e ainda o de Horta (1971) que ressalta a existência de divergências de terminologia e metodologia utilizada pelas Enfermeiras.

\section{TERMINOLOGIA NO PROCESSO DE ENFERMAGEM}

Uma vez constatada na literatura serem os jargões em enfermagem, utilizados pelos diversos autores, dotados de significados distintos, propos-se aos alunos, um estudo de alguns termos relacionados ao processo de enfermagem e ao método de resolução de problema. 
Aos alunos foi solicitado que selecionassem um termo entre os mais freqüentemente utilizados, tais como: diagnóstico de enfermagem, histórico de enfermagem, avaliação em enfermagem e outros. A seguir foi realizado levantamento bibliográfico das definições e conceitos, isto é, do significado dado pelos autores ao termo selecionado.

Uma vez feita a coletânea dos dados passou-se a análise semântica dos mesmos, observando-se a divergência de significado e/ou significante pelos autores.

Isto pode ser exemplificado ao se tomar citações ou emprego dos termos como os relatos a seguir: "Processo de enfermagem é o processo"..., ou mesmo "processo de enfermagem é o método"..., onde se observa definições inạdequadas com explicações sobre o uso da metodologia em lugar de definí-lo. Este tipo de achado observou-se também em relação a "histórico" ao ser definido como um "roteiro" perdendo-se o significado denotativo.

Foi observado também a utilização de "diagnóstico" e "avaliação" como sinônimos, ou seja, a utilização de dois significantes para um mesmo significado. Este achado leva-nos a reflexão da necessidade de estudos neste campo pois, se "diagnóstico" e "avaliação" têm o mesmo significado na comunidade, porque constituirem duas etapas do processo de enfermagem?

Também se observou serem "consulta de enfermagem" e "processo de enfermagem" apresentarem o mesmo significado. Questiona-se se estes termos apresentam realmente o mesmo significado, se são significantes distintos ou conceitos diferentes utilizados não adequadamente pelos usuários.

De forma geral os termos empregados pelos diferentes autores estudados não apresentaram relação significante/significado, dificultando a comunicação entre profissionais.

A partir dos relatos das observações dos alunos tornou-se possivel identificar um fator que pode ser limitante no avanço da compreensão da essência do método e sua aplicabilidade à prática: o significado de cada fase.

Estudos desta natureza permitem perceber a relevância de ministrar cursos, especialmente em nivel de Pós-Graduação, que propiciem a reflexão crítica e ofereçam novas abordagens para a compreensão de determinados fenômenos.

Neste sentido nosso curso num primeiro momento, estimulou a reflexão a fim de possibilitar a compreensão da Enfermagem na sua historicidade, identificando as transformaçōes que ocorram na práxis e a introdução de novas terminologias.

Em relação à terminologia, verificou-se, como já foi mencionado, divergências na sua designação e utilização, fatos estes que podem se constituir em limitantes para a aplicação prática ou para o próprio desenvolvimento do conhecimento. 


\section{REFERENCIAS BIBLIOGRÁFICAS}

ANGERAMI, E.L.S. \& BOEMER, M.R. Avaliação do estado das teorias de enfermagem. Anais do 39 Seminário Nacional de Pesquisa em Enfermagem. Ed. Univ. Fed. Santa Catarina, Florianópolis, 1984, p. 249-269.

BLOCH, D. Some crucial terms in nursing. What do they really mean? Nursing Outlook, $22(11): 689-694,1974$.

CARVAlHo, J.E. \& LOZER, H. Bases para a politica da ABEn. Rev. Bras. Enf., 22(4-5-6): 228-6, 1969.

HENDERSON, V. The nursing process - is the title right? Journal of Advanced Nursing 7, - 103-109, 1982.

HORTA, W.A. A metodologia do proceso de enfermagem - Revista Brasileira de Enfermagem $24(6): 81-95,1971$.

HORTA, W.A. Dor: seu signiffcado psicológico para estudantes e docentes de enfermagem e psicologia. Enf. Novas Dimensoes, 2(1):1-4, 1976.

HORTA, W.A. Processo de Enfermagem. São Paulo. EPU/EDUSP, 1979.

HORTA, W.A. \& KANNEBLEY, Z.M. Avaliação da dor em pacientes submetídos à cirurgia da tireóide pela aplicação do método da escala Diferencial Semantica de Osgood.

LANE, B.J. \& RAE, D.I. The prejudice of language: Effects of word choise on impressions formed by nurses. Nursing Papers, 15(1):21-33, 1983.

PAIS, C.T. Monografias de semiotica e lingüistica (apresentação da obra) in: A.J. Greimas Semiotica do discurso cientifico. Da Modalidade (Trad. de Cidmar Teodoro Pais, original, 1976). São Paulo. 1976). São Paulo. Ed. Difel - 1976.

SOMOES, C. Contribuigao ao estudo da terminologia bdsica de enfermagem no Brasil Taxionomia e Conceituaço. Rio de Janeiro (Monografia de Mestrado), 1980. 